\title{
Upward Shift and Steepening of the Blood Pressure Response to Exercise in Hypertensive Subjects at High Altitude
}

Sergio Caravita, MD;* Andrea Faini, MSc, PhD;* Claudia Baratto, MD; Grzegorz Bilo, MD, PhD; Josè Luis Macarlupu, MSc, PhD; Morin Lang, PhD; Miriam Revera, MD, PhD; Carolina Lombardi, MD, PhD; Francisco C. Villafuerte, MSc, PhD; Piergiuseppe Agostoni, MD, PhD; Gianfranco Parati, MD, PhD

Background-Acute exposure to high-altitude hypobaric hypoxia induces a blood pressure rise in hypertensive humans, both at rest and during exercise. It is unclear whether this phenomenon reflects specific blood pressure hyperreactivity or rather an upward shift of blood pressure levels. We aimed at evaluating the extent and rate of blood pressure rise during exercise in hypertensive subjects acutely exposed to high altitude, and how these alterations can be counterbalanced by antihypertensive treatment.

Methods and Results-Fifty-five subjects with mild hypertension, double-blindly randomized to placebo or to a fixed-dose combination of an angiotensin-receptor blocker (telmisartan $80 \mathrm{mg}$ ) and a calcium-channel blocker (nifedipine slow release $30 \mathrm{mg}$ ), performed a cardiopulmonary exercise test at sea level and after the first night's stay at $3260 \mathrm{~m}$ altitude. High-altitude exposure caused both an $8 \mathrm{~mm} \mathrm{Hg}$ upward shift $(P<0.01)$ and a $0.4 \mathrm{~mm} \mathrm{Hg} / \mathrm{mL} / \mathrm{kg}$ per minute steepening $(P<0.05)$ of the systolic blood pressure/oxygen consumption relationship during exercise, independent of treatment. Telmisartan/nifedipine did not modify blood pressure reactivity to exercise (blood pressure/oxygen consumption slope), but downward shifted $(P<0.001)$ the relationship between systolic blood pressure and oxygen consumption by $26 \mathrm{~mm} \mathrm{Hg}$, both at sea level and at altitude. Muscle oxygen delivery was not influenced by altitude exposure but was higher on telmisartan/nifedipine than on placebo $(P<0.01)$.

Conclusions - In hypertensive subjects exposed to high altitude, we observed a hypoxia-driven upward shift and steepening of the blood pressure response to exercise. The effect of the combination of telmisartan/nifedipine slow release outweighed these changes and was associated with better muscle oxygen delivery.

Clinical Trial Registration-URL: http://www.clinicaltrials.gov. Unique identifier: NCT01830530. (J Am Heart Assoc. 2018;7: e008506. DOI: 10.1161/JAHA.117.008506.)

Key Words: blood pressure • exercise physiology • high altitude • hypoxia • oxygen consumption

$I_{\text {to }}^{n}$ n previous articles, we demonstrated that acute exposure to high-altitude hypobaric hypoxia induces a blood pressure (BP) rise in subjects with hypertension, both at rest over the 24 hours and during exercise, ${ }^{1-3}$ likely through chemoreflex-induced sympathetic activation. ${ }^{4-6}$ Moreover, we also showed that the combination treatment with telmisartan and sustained-release formulation of nifedipine gastrointestinal therapeutic system formulation (GITS) is able to lower BP levels during exercise not only at sea level but also at high altitude, as compared with placebo. However, we previously

From the Department of Cardiovascular, Neural and Metabolic Sciences, S. Luca Hospital, IRCCS Istituto Auxologico Italiano, Milan, Italy (S.C., A.F., C.B., G.B., M.R., C.L., G.P.); Department of Medicine and Surgery, University of Milano-Bicocca, Milan, Italy (C.B., G.B., C.L., G.P.); Laboratorio de Fisiologia Comparada, Facultad de Ciencias y Filosofia, Universidad Peruana Cayetano Heredia, Lima, Peru (J.L.M., F.C.V.); Department de Ciencias de la Rehabilitación y del Movimiento Humano, Universidad de Antofagasta, Chile (M.L.); Centro Cardiologico Monzino, IRCCS, Milan, Italy (P.A.); Department of Clinical Sciences and Community Health, University of Milan, Italy (P.A.).

Accompanying Data S1, Tables S1, S2 and Figures S1, S2 are available at http://jaha.ahajournals.org/content/7/12/e008506/DC1/embed/inline-supplementarymaterial-1.pdf

* Dr Caravita and Dr Faini contributed equally to this work.

Correspondence to: Gianfranco Parati, MD, PhD, Department of Cardiovascular Neural and Metabolic Sciences, S. Luca Hospital, Istituto Auxologico Italiano \& University of Milan-Bicocca, Piazzale Brescia 20, Milan 20149, Italy. E-mail: gianfranco.parati@unimib.it

Received February 14, 2018; accepted April 27, 2018.

(C) 2018 The Authors. Published on behalf of the American Heart Association, Inc., by Wiley. This is an open access article under the terms of the Creative Commons Attribution-NonCommercial License, which permits use, distribution and reproduction in any medium, provided the original work is properly cited and is not used for commercial purposes. 


\section{Clinical Perspective}

\section{What Is New?}

- We constructed a multipoint blood pressure/oxygen consumption relationship during exercise in hypertensive individuals randomized either to placebo or to an antihypertensive combination treatment (nifedipine/telmisartan gastrointestinal therapeutic system formulation), as a way to normalize blood pressure levels and rate of increase for metabolic demands and cardiac output changes.

\section{What Are the Clinical Implications?}

- High blood pressure during exercise at altitude does not seem to be a physiological compensation for reduced blood oxygen content but rather a potentially harmful mechanism in hypertensive individuals whose hypertension is not adequately controlled at sea level.

- Hypertensive subjects exposed to high altitude hypobaric hypoxia display both an upward shift and a steepening of the blood pressure response to exercise.

- Combination treatment with telmisartan-nifedipine gastrointestinal therapeutic system formulation downward shifted blood pressure levels and improved muscle oxygen delivery during exercise.

reported $\mathrm{BP}$ at each workload of exercise ${ }^{2}$ or immediately after exercise only, ${ }^{3}$ without estimating the possible changes in the rate of BP increase during exercise. Furthermore, workload is an imprecise surrogate measure for exercise intensity because there is a considerable variability in the relationship between workload and oxygen consumption. Indeed, it is a common experience that a given task (eg, climbing stairs, which may correspond to a given workload) may engender extremely different responses in terms of dyspnea, fatigue, or palpitations when conducted either at sea level or at high altitude. For these reasons, in a previous report of ours, we also tried to normalize BP for oxygen consumption $\left(\mathrm{VO}_{2}\right)$, the latter being acknowledged as a more precise indicator of cardiac output and metabolic needs imposed by exercise than is the measure of workload. However, we assessed this ratio only at peak exercise and not dynamically throughout the different exercise steps. ${ }^{2}$

Thus, it remains debated whether the BP rise during exercise at high altitude may be the result only of an upward shift of the BP levels to higher "reference" values or whether there might be a component of BP hyperreactivity induced by exercise in hypoxic conditions. ${ }^{7,8}$ Moreover, it is unclear whether antihypertensive therapy would just result in a downward shift of BP levels, or if it might also reduce the rate of BP increase occurring during exercise, thus modulating BP hyperreactivity. These questions were not addressed in our previous article, ${ }^{1-3}$ and discordant answers were found on the basis of the results of the few studies that addressed these issues up to now. ${ }^{7-9}$

Because of these discrepant or incomplete pieces of evidence, the clinical significance of BP rise during exercise at altitude in subjects with hypertension has been questioned recently. ${ }^{9}$ In an attempt to clarify the above-mentioned open issues, we have reanalyzed exercise data from the HIGHCAREANDES (High Altitude Cardiovascular Research in the Andes) Lowlanders Study, obtained both at sea level and at high altitude.

\section{Methods}

\section{Population}

One hundred individuals with grade I essential hypertension (conventional systolic BP $140-159 \mathrm{~mm} \mathrm{Hg}$ or conventional diastolic BP 90-99 mm Hg and mean daytime systolic BP $\geq 135$ and $<150 \mathrm{~mm} \mathrm{Hg}$ and/or mean daytime diastolic BP $\geq 85$ and $<95 \mathrm{~mm} \mathrm{Hg}$ ) and no significant comorbidities, either untreated or having previously stopped antihypertensive therapy for 4 weeks, were enrolled in the frame of the HIGHCARE-ANDES study. ${ }^{1}$ All subjects were sea-level residents. None of the subjects had a history of sleep apnea. A full list of inclusion and exclusion criteria are reported in Data S1.

The data, analytic methods, and study materials will not be made available to other researchers for purposes of reproducing the results or replicating the procedure.

The study protocol was approved by the Ethics Committee of Istituto Auxologico Italiano (Milan, Italy) and Universidad Peruana Cayetano Heredia (Lima, Peru), and was conducted in accordance with the Declaration of Helsinki. All subjects gave written informed consent to participate.

After enrollment, subjects were randomized to receive a fixed-dose combination of telmisartan $80 \mathrm{mg} /$ nifedipine-GITS $30 \mathrm{mg}$ or placebo according to a double-blind study design.

Of the study population, 56 randomly chosen individuals participated in the exercise substudy, in which they repeatedly performed a symptom-limited cardiopulmonary exercise test (CPET) on a cycle-ergometer in different study settings.

\section{Cardiopulmonary Exercise Test}

To familiarize patients with the medical personnel and with the procedure, a CPET was performed whenever possible at sea level before randomization, ie, in absence of treatment. The study protocol then focused on CPET performance in 2 conditions:

1. At sea level, after 6 weeks of randomized treatment with placebo or telmisartan/nifedipine-GITS;

2. At $3260 \mathrm{~m}$ above sea level (Huancayo, Peru) 1 week after the previous CPET. 
Details on the CPET methodology are provided in Data S1.

For each subject, systolic BP at each step of exercise was plotted against $\mathrm{VO}_{2}$ in order to calculate the $\mathrm{BP}$ intercept and the slope of their relationship, as a way to normalize BP increment for metabolic demand and cardiac output increase. $^{10}$ In fact, a constant linear relationship between cardiac output and $\mathrm{VO}_{2}$ has been demonstrated at sea level as well as at altitude. ${ }^{11-13}$ Similarly, the multipoint $\mathrm{VO}_{2}$ /work relationship was constructed, its slope reflecting muscle oxygen delivery (the higher the slope, the better the oxygen delivery). ${ }^{14}$

\section{Other Measurements}

In the morning before any CPET, we recorded BP at rest (3 measurements) with the patient in a seated position, using a validated oscillometric device (UA-767 Plus; A\&D, Tokyo, Japan), together with heart rate and blood oxygen saturation (Masimo Rad-5; Masimo Corporation, Irvine, CA, USA). At high altitude, patients were questioned for the occurrence of acute mountain sickness symptoms, using the Lake Louise Score. ${ }^{15}$

\section{Statistics}

Continuous variables are reported as means \pm standard deviations. Distribution of the variables in terms of proximity to normal and the homogeneity of variances were detected by the Shapiro-Wilk test and Bartlett test, respectively. To assess the effects of high altitude and treatment on the variables of interest, we used the linear mixed-effects models with contrasts a posteriori accounting for repeated measurements, ${ }^{16}$ fitting the models by maximizing the restricted loglikelihood. For multiple post hoc comparisons we used the algorithm that controls the expected rate of false-positive results for all positive results (false discovery rate).

To evaluate the difference in general characteristics between the placebo and active groups we used a 2-sample Wilcoxon signed-rank test for age and a 2-sample t test with pooled estimates of the sample variance for the other homoscedastic and normally distributed variables.

An $\alpha$ level of 0.05 was used for all hypothesis tests. All data analyses were performed using R Core Team (2017, Vienna, Austria).

\section{Results}

One male subject withdrew his consent to be studied before high-altitude exposure. Thus, data from 55 subjects were available for analysis (Figure S1). At sea level, before treatment, the demographic, anthropometric, and BP values did not differ between the group randomized to combination treatment or to placebo (Table 1). As shown in Table S1, highaltitude exposure caused a small BP increase at rest that was statistically significant only for diastolic BP values, with a concomitant small increase in heart rate and a significant reduction of blood oxygen saturation. Compared to placebo, telmisartan/nifedipine-GITS significantly reduced BP values both at sea level and at high altitude. At high altitude, patients developed mild symptoms of acute mountain sickness, without treatment-related differences (Lake Louise Score $2.0 \pm 2.1$ versus $2.0 \pm 1.7, P=0.925$, for telmisartan/nifedipine-GITS and placebo, respectively).

\section{Blood Pressure During Exercise}

We built a multipoint ( $\geq 3$ points) systolic $\mathrm{BP} / \mathrm{VO}_{2}$ relationship that was linear, with a coefficient of determination $\geq 0.70$ (on average, 0.92 ) in $99 \%$ of the tests. The data point from 2 exemplificative cases ( 1 on active treatment and 1 on placebo) are plotted in Figure 1.

Estimated marginal means revealed that high-altitude exposure upward shifted $(+8 \mathrm{~mm} \mathrm{Hg})$ and steepened (+0.4 mm Hg/mL/kg per minute) the relationship between systolic BP and $\mathrm{VO}_{2}$ (Table 2 and Figure 2), independent of treatment, and that active treatment downward shifted $(-26 \mathrm{~mm} \mathrm{Hg})$ the relationship between systolic $\mathrm{BP}$ and $\mathrm{VO}_{2}$ without affecting its slope.

\section{Cardiorespiratory Variables During Exercise}

As shown in Table 3, in patients completing a CPET, highaltitude exposure significantly affected many variables. The achieved peak respiratory quotient was always $>1.00$, indicating achievement of adequately intense exercise levels. As previously reported, at peak exercise both workload and

Table 1. General Baseline Characteristics of the Study Population Before Treatment Randomization at Sea Level

\begin{tabular}{|l|l|l|l|}
\hline & T/N-GITS & PL & $P$ Value \\
\hline $\mathrm{N}$ (men) & $27(13)$ & $28(16)$ & $\ldots$ \\
\hline Age, y & $50 \pm 8$ & $53 \pm 9$ & 0.235 \\
\hline Weight, kg & $72 \pm 13$ & $79 \pm 14$ & 0.065 \\
\hline Height, cm & $162 \pm 8$ & $166 \pm 9$ & 0.113 \\
\hline BMl, kg/m ${ }^{2}$ & $27.3 \pm 4.0$ & $28.6 \pm 3.6$ & 0.220 \\
\hline Office SBP, mm Hg & $139 \pm 12$ & $145 \pm 12$ & 0.088 \\
\hline Office DBP, mm Hg & $90 \pm 8$ & $93 \pm 9$ & 0.191 \\
\hline Office HR, bpm & $70 \pm 7$ & $73 \pm 8$ & 0.090 \\
\hline
\end{tabular}

Data are expressed as mean \pm standard deviations. BMI indicates body mass index; DBP, diastolic blood pressure; HR, heart rate; PL, placebo; SBP, systolic blood pressure; T/NGITS, telmisartan $80 \mathrm{mg} /$ nifedipine-GITS $30 \mathrm{mg}$. 


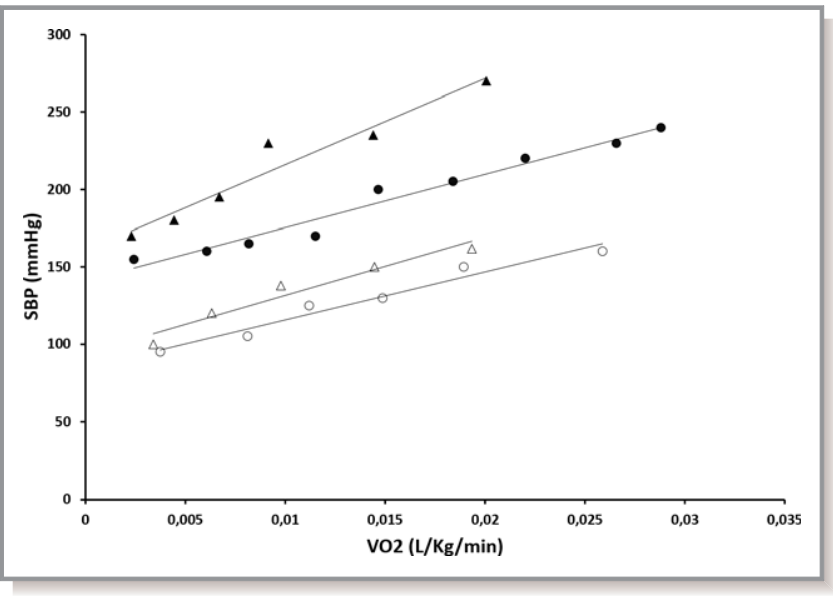

Figure 1. Multipoint relationship between systolic blood pressure and oxygen consumption in 2 exemplificative cases randomized to active treatment (white) and to placebo (black), exercising both at sea level (circles) and at altitude (triangles). HA indicates high altitude; SBP, systolic blood pressure; SL, sea level; T/N-GITS, telmisartan $80 \mathrm{mg} /$ nifedipine-GITS $30 \mathrm{mg} ; \mathrm{VO}_{2}$, oxygen consumption.

$\mathrm{VO}_{2}$ were reduced at altitude, ${ }^{2}$ as were heart rate and blood oxygen saturation, without treatment-related differences.

$\mathrm{VO}_{2}$ /work slope was not modified by high-altitude exposure $(P=0.482)$ and always resulted higher on active treatment than on placebo $(P=0.006)$, as shown in Figure 3, Figure S2, and Table S2.

\section{Discussion}

The present study shows that subjects with mild hypertension acutely exposed to high altitude display an exaggerated, hypoxia-driven BP response to exercise as a result both of an upward shift of BP levels at altitude and a steepening of the $\mathrm{BP} / \mathrm{VO}_{2}$ slope. Moreover, our data demonstrate that pharmacological treatment (telmisartan/nifedipine-GITS combination) downward shifted the BP levels both at sea level and at altitude, albeit not directly contrasting the steepening of BP/ $\mathrm{VO}_{2}$ slope at altitude. Finally, the telmisartan/nifedipine-GITS combination seemed to improve muscle oxygen delivery during exercise, both at sea level and at altitude.

\section{Blood Pressure Response During Exercise at High Altitude}

During incremental exercise, cardiac output increases progressively to match metabolic demand, while systemic vascular resistance is only slightly reduced, thus resulting in a BP rise. Aging, presence of hypertension, and environmental conditions may modify such physiological response to physical effort, upward shifting, or even steepening the BP-cardiac output relationship. ${ }^{17-20}$ This may hold true also for forms of hypoxia-related BP rise commonly encountered in clinical practice, such as those observed in case of obstructive sleep apnea episodes, which can be characterized by nocturnal hypertension related to hypoxia and sympathetic activation. ${ }^{21}$ Indeed, we found that exposure to acute hypobaric hypoxia was responsible for both an upward shift and steepening of the $\mathrm{BP}$ response to exercise in our middle-aged, mildly hypertensive individuals.

We related systolic $\mathrm{BP}$ to $\mathrm{VO}_{2}$ as a way to normalize $\mathrm{BP}$ increase for metabolic demand and cardiac output increase, ${ }^{10}$ given the need to compare the different conditions in which we assessed hypertensive individuals in our study. Indeed, it has been previously shown that the linear relationship between $\mathrm{VO}_{2}$ and cardiac output is maintained at high altitude hypobaric hypoxia. ${ }^{11-13}$ This means that at any given level of effort, as optimally represented by any $\mathrm{VO}_{2}$, systolic $\mathrm{BP}$ will be significantly higher at $3260 \mathrm{~m}$ altitude than at sea level, irrespective of treatment. Based on our results, a patient with mild hypertension exercising at high altitude on average will present with a systolic BP about $10 \mathrm{~mm} \mathrm{Hg}$ higher than at sea level during very-low-intensity exercise due to the upward shift of the $\mathrm{BP} / \mathrm{VO}_{2}$ relationship. However, given also the steepening of such relationship, $\mathrm{BP}$ increase will be even more marked when approaching higher exercise intensities (for instance, $+16 \mathrm{~mm} \mathrm{Hg}$ as compared to sea level for a $\mathrm{VO}_{2}$ of $20 \mathrm{~mL} / \mathrm{kg}$ per minute, ie, a $\mathrm{VO}_{2}$ which is normally achieved at moderate intensity exercise). In other words, the mean effect of high altitude on the slope of the systolic $\mathrm{BP} / \mathrm{VO}_{2}$ relationship seems to be small in the case of mild exercise and becomes more evident when $\mathrm{VO}_{2}$ is higher. This exaggerated $\mathrm{BP}$ rise could be a

Table 2. Slopes and Intercepts of the Relationship Between Systolic Blood Pressure and Oxygen Consumption During Exercise in the Different Study Conditions and According to Treatment Group

\begin{tabular}{|c|c|c|c|c|c|c|c|}
\hline & \multicolumn{2}{|l|}{ SL } & \multicolumn{2}{|l|}{$\mathrm{HA}$} & $P_{\text {treatment }}$ & $P_{\text {visit }}$ & $P_{\text {treatment } \times \text { visit }}$ \\
\hline $\mathrm{SBP} \mathrm{NO}_{2}$ slope & $3.2 \pm 1.1$ & $3.9 \pm 1.6$ & $3.7 \pm 1.5$ & $4.2 \pm 1.6$ & 0.091 & 0.026 & 0.506 \\
\hline
\end{tabular}

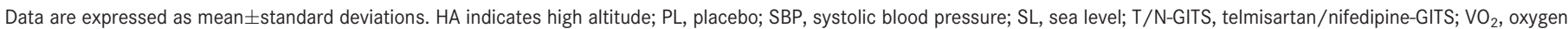
consumption. 


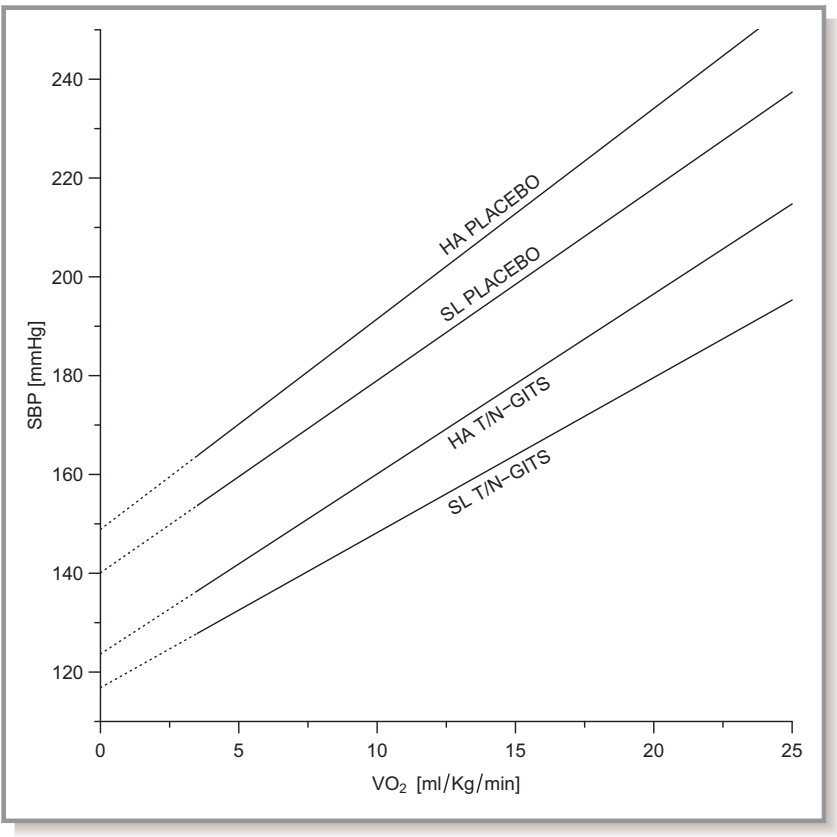

Figure 2. Systolic blood pressure as a function of oxygen consumption during exercise in the different study settings and according to treatment group. In this exemplificative figure, mean slopes for each treatment group in each study condition are plotted, with the relative intercepts. Continuous lines represent the blood pressure response in a physiological range of $\mathrm{VO}_{2}$ values during exercise. Dashed lines represent extrapolation until the systolic blood pressure intercept on the $y$-axis. HA indicates high altitude; SBP, systolic blood pressure; SL, sea level; T/N-GITS, telmisartan $80 \mathrm{mg} /$ nifedipine-GITS $30 \mathrm{mg} ; \mathrm{VO}_{2}$, oxygen consumption.

consequence of altitude-induced reflex activation. We previously described that during exercise the ventilatory equivalents for oxygen and $\mathrm{CO}_{2}$ were both higher at altitude compared to sea level, ${ }^{2}$ likely as a consequence of augmented peripheral chemoreflex input ${ }^{6,22}$ and fluid accumulation along the alveolar capillary membrane. ${ }^{23}$

Our data, collected after a 1-night stay at altitude are consistent with real-life hypoxic exposure and diverge from other data provided in hyperacute hypoxic settings in laboratory conditions, ${ }^{9}$ where it was suggested that hypoxiainduced vasodilation might counteract sympathetic-induced vasoconstriction with an overall neutral net effect on BP.

\section{Effects of Antihypertensive Therapy}

The net effect of active treatment was a downward shift of the $\mathrm{BP} / \mathrm{VO}_{2}$ relationship of about $26 \mathrm{~mm} \mathrm{Hg}$. However, it did not completely counteract hypoxia-driven BP hyperreactivity to exercise, given that the systolic $\mathrm{BP} / \mathrm{VO}_{2}$ slope was higher at altitude than at sea level independent of treatment. Nevertheless, the magnitude of the BP downward shift induced by telmisartan/nifedipine-GITS was remarkably greater than the hypoxia-induced BP rise, especially at low exercise intensities.

Moreover, the $\mathrm{VO}_{2}$ /work slope was higher on active treatment than on placebo, meaning that muscle oxygen delivery and utilization was more efficient on telmisartan/ nifedipine-GITS, likely as a direct result of BP reduction. ${ }^{24}$ This did not translate into improved exercise capacity; however, it did not result in any adverse effect nor in a reduction of physical performance. This is at variance from other antihypertensive drugs suggested to be used at altitude, such as some beta blockers, that may have a negative impact on ventilatory control and exercise capacity in hypoxic conditions. ${ }^{25-27}$ Moreover, the slope of the $\mathrm{VO}_{2}$ /work relationship was unaffected by high altitude $(3260 \mathrm{~m})$ both in the active treatment group and in the placebo group, suggesting that during effort, compensatory mechanisms allow oxygen delivery to muscles to remain stable. There are several possible compensatory mechanisms, including blood flow redistribution, increased oxygen extraction, and increased cardiac output for a given work rate. ${ }^{11-13}$

It should be noted that the $\mathrm{VO}_{2}$ /work relationship was a straight line throughout the entire exercise, which means that above the anaerobic threshold, when $\mathrm{VO}_{2}$ is cardiac output dependent, compensatory mechanisms and likely -in this specific setting of acute high-altitude exposure-only an

Table 3. Cardiopulmonary Variables at Peak Exercise in the 2 Treatment Groups in the Different Study Conditions

\begin{tabular}{|c|c|c|c|c|c|c|c|}
\hline & \multicolumn{2}{|l|}{$\mathrm{SL}$} & \multicolumn{2}{|l|}{ HA } & $P_{\text {treatment }}$ & $P_{\text {time }}$ & $P_{\text {treatment } \times \text { visit }}$ \\
\hline Workload, watts & $121 \pm 32$ & $138 \pm 44$ & $105 \pm 27$ & $118 \pm 31$ & 0.261 & $<0.001$ & 0.271 \\
\hline $\mathrm{RQ}$ & $1.21 \pm 0.07$ & $1.25 \pm 0.11$ & $1.20 \pm 0.10$ & $1.19 \pm 0.08$ & 0.622 & 0.006 & 0.068 \\
\hline $\mathrm{VE}, \mathrm{L} / \mathrm{min}$ & $74 \pm 20$ & $83 \pm 25$ & $77 \pm 20$ & $78 \pm 22$ & 0.386 & 0.957 & 0.158 \\
\hline $\mathrm{HR}$, beats/min & $163 \pm 16$ & $166 \pm 14$ & $160 \pm 15$ & $159 \pm 13$ & 0.711 & $<0.001$ & 0.065 \\
\hline
\end{tabular}

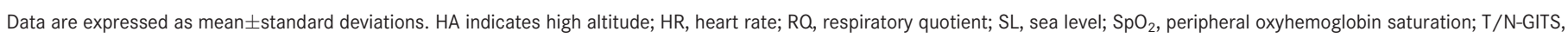
telmisartan $80 \mathrm{mg} /$ nifedipine-GITS $30 \mathrm{mg}$; VE, minute ventilation; $\mathrm{VO}_{2}$, oxygen consumption. 


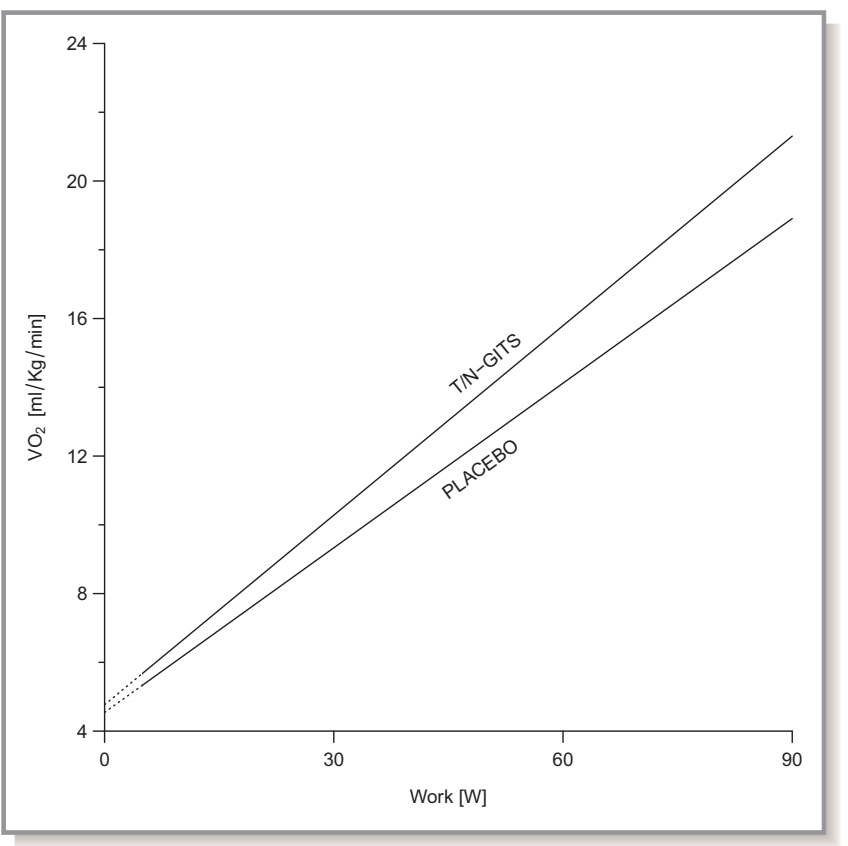

Figure 3. Relationship between oxygen consumption and workload in the 2 treatment groups. Continuous lines represent the mean slope value for each treatment group in a physiological range of workload. Dashed lines represent extrapolation until the oxygen consumption intercept on the $y$-axis. T/N-GITS indicates telmisar$\tan 80 \mathrm{mg} /$ nifedipine-GITS $30 \mathrm{mg} ; \mathrm{VO}_{2}$, oxygen consumption.

increase in oxygen extraction keep the relationship unchanged. ${ }^{12,13}$

\section{Study Limitations}

Some limitations of the present study must be acknowledged. Exercise data were collected in subjects with mild hypertension after a 1-night stay at $3260 \mathrm{~m}$ above sea level. Thus, our results refer to this specific cohort and to this specific time window during hypoxia exposure, but they may not apply to subjects with more severe degrees of hypertensive disease, to exposure to other altitudes, and/or to longer high-altitude permanence.

Our study population was predominantly composed of middle-aged Peruvian sea-level residents. Thus, further studies are needed to show whether our results can be safely applied to other ethnicities or to wider age ranges.

We did not focus our analysis on diastolic BP because of the known low accuracy of noninvasive diastolic BP readings during exercise. ${ }^{28}$

\section{Perspectives}

Subjects with mild hypertension displayed both an upward shift and a steepening of the BP response to exercise during acute exposure to high altitude, whose clinical implications, in particular in subjects characterized by an increased level of cardiovascular risk, should be better elucidated. The effect of a combination of a long-acting calcium-channel blocker and a long-acting angiotensin-receptor blocker outweighed the hypoxia-induced BP rise during exercise.

\section{Acknowledgments}

We thank Gian Piero Babbi and Stefano Ariotti (TaoMed) for the technical support given to this study.

\section{Sources of Funding}

The HIGHCARE-ANDES project was supported by an unrestricted grant from Bayer Healthcare, Germany.

\section{Disclosures}

Parati received speaker's fee or consultation fee from Bayer Healthcare, Daiichi Sankyo, Menarini, CVRx, Pfizer Inc, Servier. Bilo received a speaker's fee from Bayer Healthcare. Agostoni has been consultant for Menarini Int. and Bayer Healthcare, and has received speaker's fees from Novartis, Daiichi Sankyo, and Servier. The remaining authors have no disclosures to report.

\section{References}

1. Bilo G, Villafuerte FC, Faini A, Anza-Ramírez C, Revera M, Giuliano A, Caravita S, Gregorini F, Lombardi C, Salvioni E, Macarlupu JL, Ossoli D, Landaveri L, Lang M, Agostoni P, Sosa JM, Mancia G, Parati G. Ambulatory blood pressure in untreated and treated hypertensive patients at high altitude: the High Altitude Cardiovascular Research-Andes Study. Hypertension. 2015;65:12661272.

2. Caravita S, Faini A, Bilo G, Villafuerte FC, Macarlupu JL, Lang M, Salvioni E, Revera M, Giuliano A, Gregorini F, Mancia G, Agostoni P, Parati G. Blood pressure response to exercise in hypertensive subjects exposed to high altitude and treatment effects. J Am Coll Cardiol. 2015;66:28062807.

3. Lang M, Faini A, Caravita S, Bilo G, Anza-Ramìrez C, Villafuerte FC, Macarlupu JL, Salvioni E, Agostoni P, Parati G. Blood pressure response to six-minute walk test in hypertensive subjects exposed to high altitude: effects of antihypertensive combination treatment. Int J Cardiol. 2016;219:27-32.

4. Somers VK, Mark AL, Abboud FM. Potentiation of sympathetic nerve responses to hypoxia in borderline hypertensive subjects. Hypertension. 1988;11:608-612.

5. Wolfel EE, Selland MA, Mazzeo RS, Reeves JT. Systemic hypertension at 4,300 $\mathrm{m}$ is related to sympathoadrenal activity. J Appl Physiol. 1994;76:16431650.

6. Hainsworth R, Drinkhill MJ, Rivera-Chira M. The autonomic nervous system at high altitude. Clin Auton Res. 2007;17:13-19.

7. D’Este D, Mantovan R, Martino A, D'Este F, Artusi L, Allibardi P, Franceschi M, Zerio C, Pascotto P. The behavior of the arterial pressure at rest and under exertion in normotensive and hypertensive subjects exposed to acute hypoxia at a median altitude. G Ital Cardiol. 1991;21:643-649.

8. Savonitto S, Cardellino G, Doveri G, Pernpruner S, Bronzini R, Milloz N, Colombo MD, Sardina M, Nassi G, Marraccini P. Effects of acute exposure to altitude $(3,460 \mathrm{~m})$ on blood pressure response to dynamic and isometric exercise in men with systemic hypertension. Am J Cardiol. 1992;70:14931497.

9. Winkler L, Lhuissier FJ, Richalet JP. Systemic blood pressure at exercise in hypoxia in hypertensive and normotensive patients. I Hypertens. 2017;35:2402-2410. 
10. Guazzi M, Adams V, Conraads V, Halle M, Mezzani A, Vanhees L, Arena R, Fletcher GF, Forman DE, Kitzman DW, Lavie CJ, Myers J; European Association for Cardiovascular Prevention \& Rehabilitation; American Heart Association. EACPR/AHA Scientific Statement. Clinical recommendations for cardiopulmonary exercise testing data assessment in specific patient populations. Circulation. 2012;126:2261-2274.

11. Naeije R. Physiological adaptation of the cardiovascular system to high altitude. Prog Cardiovasc Dis. 2010;52:456-466.

12. Reeves JT, Groves BM, Sutton JR, Wagner PD, Cymerman A, Malconian MK, Rock PB, Young PM, Houston CS. Operation Everest II: preservation of cardiac function at high altitude. J Appl Physiol. 1987;63:531-539.

13. Pugh LG. Cardiac output in muscular exercise at $5,800 \mathrm{~m}(19,000 \mathrm{ft})$. J Appl Physiol. 1964;19:441-447.

14. Wasserman K, Hansen JE, Sue DY, Stringer WW, Whipp BJ. Principles of Exercise Testing and Interpretation. 4th ed. Philadelphia, PA: Lippincott Williams \& Wilkins; 2005

15. Roach RC, Bärtsch $\mathrm{P}$, Hackett $\mathrm{PH}$, Oelz O. The Lake Louise acute mountain sickness scoring system. In: Sutton JR, Houston CS, Coates A, eds. Hypoxia and Molecular Medicine. Burlington, VT: Queen City Printers Inc; 1993:272274.

16. Napoli AM, Milzman DP, Damergis JA, Machan J. Physiologic effects of altitude on recreational climbers. Am J Emerg Med. 2009;27:1081-1084.

17. Amery A, Julius S, Whitlock LS, Conway J. Influence of hypertension on the hemodynamic response to exercise. Circulation. 1967;36:231-237.

18. Julius S, Amery A, Whitlock LS, Conway J. Influence of age on the hemodynamic response to exercise. Circulation. 1967;36:222-230.

19. Levy AM, Tabakin BS, Hanson JS. Hemodynamic responses to graded treadmill exercise in young untreated labile hypertensive patients. Circulation. 1967;35:1063-1072.

20. Julius S, Conway J. Hemodynamic studies in patients with borderline blood pressure elevation. Circulation. 1968;38:282-288.
21. Parati G, Lombardi C, Castagna F, Mattaliano P, Filardi PP, Agostoni P; Italian Society of Cardiology (SIC) Working Group on Heart Failure Members. Heart failure and sleep disorders. Nat Rev Cardiol. 2016;13:389-403.

22. Caravita S, Faini A, Lombardi C, Valentini M, Gregorini F, Rossi J, Meriggi P, Di Rienzo M, Bilo G, Agostoni P, Parati G. Gender and acetazolamide effects on chemoreflex and periodic breathing during sleep at altitude. Chest. 2015;147:120-131.

23. Agostoni P, Swenson ER, Fumagalli R, Salvioni E, Cattadori G, Farina S, Bussotti M, Tamplenizza M, Lombardi C, Bonacina D, Brioschi M, Caravita S, Modesti P, Revera M, Giuliano A, Meriggi P, Faini A, Bilo G, Banfi C, Parati G. Acute high-altitude exposure reduces lung diffusion: data from the HIGHCARE Alps project. Respir Physiol Neurobiol. 2013;188:223-228.

24. Dipla K, Triantafyllou A, Kolestos N, Papadopoulos S, Sachpekidis V, Vrabas IS, Gkaliagkousi E, Zafeiridis A, Douma S. Impaired muscle oxygenation and elevated blood pressure in hypertensive patients: links with vascular stiffness. Hypertension. 2017;79:444-451.

25. Agostoni P, Contini M, Magini A, Apostolo A, Cattadori G, Bussotti M, Veglia F, Andreini D, Palermo P. Carvedilol reduces exercise-induced hyperventilation: a benefit in normoxia and a problem with hypoxia. Eur J Heart Fail. 2006;8:729735.

26. Valentini M, Revera M, Bilo G, Caldara G, Savia G, Styczkiewicz K, Parati S, Gregorini F, Faini A, Branzi G, Malfatto G, Magrì D, Agostoni P, Parati G. Effects of beta-blockade on exercise performance at high altitude: a randomized, placebo-controlled trial comparing the efficacy of nebivolol versus carvedilol in healthy subjects. Cardiovasc Ther. 2012;30:240-248.

27. Contini M, Apostolo A, Cattadori G, Paolillo S, lorio A, Bertella E, Salvioni E, Alimento M, Farina S, Palermo P, Loguercio M, Mantegazza V, Karsten M, Sciomer S, Magrì D, Fiorentini C, Agostoni P. Multiparametric comparison of CARvedilol, vs. NEbivolol, vs. BIsoprolol in moderate heart failure: the CARNEBI trial. Int J Cardiol. 2013;168:2134-2140.

28. Rasmussen PH, Staats BA, Driscoll DJ, Beck KC, Bonekat HW, Wilcox WD. Direct and indirect blood pressure during exercise. Chest. 1985;87:743-748. 
SUPPLEMENTAL MATERIAL 


\section{Data S1.}

\section{Study protocol: complete inclusion and exclusion criteria [1]}

Subjects were included if they fulfilled the following criteria: age 18-65 years; permanent residence at low $(<500 \mathrm{~m}$ ) altitude; conventional systolic blood pressure (BP) 140-159 mmHg or conventional diastolic BP 90-99 mmHg and mean daytime systolic BP $\geq 135$ and $<150 \mathrm{mmHg}$ and/or mean daytime diastolic BP $\geq 85$ and $<95 \mathrm{mmHg}$ in subjects untreated or after 4 weeks of washout from previous treatment; written informed consent to participate in the study. The exclusion criteria were: conventional systolic $\mathrm{BP} \geq 150 \mathrm{mmHg}$ and/or conventional diastolic $\mathrm{BP} \geq 95 \mathrm{mmHg}$ in treated subjects; regular use of two or more antihypertensive drugs (with the exception of subjects on two antihypertensive drugs in low doses); treated antihypertensive subjects in whom withdrawal of treatment was deemed unethical; contraindications to angiotensin receptor blockers or calcium antagonists; history of serious mountain sickness; subjects who spent considerable (> 1 week) amount of time at altitudes above $2500 \mathrm{~m}$ during the 3 months preceding inclusion in the study; cardiovascular diseases other than hypertension; suspected or confirmed secondary hypertension; diabetes mellitus; serious respiratory disorders; other conditions deemed relevant by the investigators; $\mathrm{BMI} \geq 35 \mathrm{~kg} / \mathrm{m} 2$; upper arm circumference $>32 \mathrm{~cm}$; known severe obstructive sleep apnoea; pregnancy; premenopausal women not using effective contraceptive methods; elevated probability of noncompliance with the study procedures.

\section{Cardiopulmonary Exercise Test Methodology}

Cardiopulmonary Exercise Test (CPET) was always performed on a mechanically-braked cycleergometer (Monark Ergomedic 828E, Sweden). Participating individuals either wore a nose clip, while breathing through a mouthpiece, or a well-fitting Hans-Rudolph face mask, both connected 
to the mass flow sensor of the metabolic cart (Vmax SensorMedics 2200, Yorba Linda, CA, USA), allowing breath-by-breath collection of ventilation and respiratory gases.

CPET was preceded by a resting period of 3-5 minutes, and consisted in a 3-minute warm-up period (unloaded pedaling), followed by a step-incremental phase during which the work rate was increased by $30 \mathrm{~W}$ every 3 minutes, in order to allow for a more accurate BP measurement corresponding to any given workload. The threshold BP values considered to terminate the test were levels $>250 \mathrm{mmHg}$ for systolic $\mathrm{BP}$ (SBP) and/or $>120 \mathrm{mmHg}$ for diastolic BP (DBP)[2]. Heart rate (HR), by 12-lead electrocardiogram (Corina Cardiosoft, General Electrics Milwaukee, WI, USA) and peripheral oxyhemoglobin saturation $\left(\mathrm{SpO}_{2}\right)$, by ear-lobe pulse-oxymeter (NPB-295, Nellcor Puritan Bennet Inc, Plaseanton, CA, USA), were continuously recorded. Arm BP was measured noninvasively always with the same device (auscultatory method) two times at rest, during the last minute of each workload step, and at peak exercise always by the same operator blinded to the individual's treatment allocation.

Individuals were strongly encouraged to perform a maximal test, while allowing them to determine when their symptoms were so severe to stop cycling. Objective criteria for interrupting exercise were the usual ones defined by guidelines [2]. At HA, oxygen desaturation was considered an interruption criterion only if accompanied by symptoms and signs of hypoxemia.

Tests were always performed in rooms at controlled temperature $\left(19-22^{\circ} \mathrm{C}\right)$. Mean barometric pressure recorded during the tests was 750.8 \pm 1.0 Torr at SL and 516.0 \pm 1.6 Torr at HA.

Offline analysis of CPET data was performed in accordance with recommendations [2,3] by two independent observers blinded to study treatment. In case of non-agreement between them, a third independent reader analyzed the test. The average values of the cardiorespiratory variables obtained during the last minute of each step of exercise were considered representative of its 
corresponding workload. Peak exercise was defined as the exercise performed during the last 30 seconds of the test. 
Table S1. Parameters recorded in resting conditions at SL and at HA in the two treatment groups.

\begin{tabular}{|c|c|c|c|c|c|c|c|}
\hline & \multicolumn{2}{|l|}{ SL } & \multicolumn{2}{|l|}{ HA } & \multirow[b]{2}{*}{$\mathbf{p}_{\text {treatment }}$} & \multirow[b]{2}{*}{$\mathbf{P}_{\text {visit }}$} & \multirow[b]{2}{*}{$\mathbf{P}_{\text {treatment } \mathrm{x} \mathrm{visit}}$} \\
\hline & $\begin{array}{c}\text { T/N-GITS } \\
(n=27)\end{array}$ & $\begin{array}{l}P L \\
(n=28)\end{array}$ & $\begin{array}{l}\text { T/N-GITS } \\
(n=27)\end{array}$ & $\begin{array}{l}P L \\
(n=28)\end{array}$ & & & \\
\hline Office SBP & $123 \pm 16$ & $142 \pm 14$ & $124 \pm 12$ & $148 \pm 11$ & $<0.001$ & 0.122 & 0.396 \\
\hline Office DBP & $78 \pm 11$ & $92 \pm 10$ & $82 \pm 9$ & $95 \pm 10$ & $<0.001$ & 0.033 & 0.882 \\
\hline Office HR & $75 \pm 9$ & $75 \pm 10$ & $82 \pm 13$ & $77 \pm 8$ & 0.200 & 0.049 & 0.170 \\
\hline $\mathrm{SpO}_{2}$ & $98 \pm 2$ & $98 \pm 2$ & $90 \pm 3$ & $90 \pm 4$ & 0.832 & $<0.001$ & 0.486 \\
\hline
\end{tabular}

$\mathrm{SL}=$ sea level; HA=high altitude; T/N-GITS= telmisartan $80 \mathrm{mg} /$ nifedipine-GITS 30 mg; PL=placebo; $\mathrm{SBP}=$ systolic blood pressure $(\mathrm{mmHg}) ; \mathrm{DBP}=$ diastolic blood pressure $(\mathrm{mmHg}) ; \mathrm{HR}=$ heart rate $(\mathrm{bpm})$; $\mathrm{SpO}_{2}=$ peripheral oxyhemoglobin saturation. 
Table S2. Slopes and intercepts of the relationship between oxygen consumption and workload during exercise in the different study conditions and according to treatment group.

\begin{tabular}{|c|c|c|c|c|c|c|c|}
\hline & \multicolumn{2}{|l|}{ SL } & \multicolumn{2}{|l|}{ HA } & \multirow[b]{2}{*}{$\mathbf{p}$ treatment } & \multirow[b]{2}{*}{$\mathbf{p}_{\text {visit }}$} & \multirow[b]{2}{*}{$\mathbf{p}_{\text {treatment } x \text { visit }}$} \\
\hline & $\begin{array}{l}\text { T/N-GITS } \\
(n=25)\end{array}$ & $\begin{array}{l}P L \\
(n=23)\end{array}$ & $\begin{array}{l}\text { T/N-GITS } \\
(n=23)\end{array}$ & $\begin{array}{l}P L \\
(n=22)\end{array}$ & & & \\
\hline $\begin{array}{l}\mathrm{VO}_{2} / \text { work intercept } \\
(\mathrm{mL} / \mathrm{Kg} / \mathrm{min})\end{array}$ & $4.7 \pm 0.9$ & $4.3 \pm 0.4$ & $4.8 \pm 1.0$ & $4.8 \pm 1.4$ & 0.305 & 0.062 & 0.234 \\
\hline $\begin{array}{l}\mathrm{VO}_{2} / \text { work slope } \\
\text { (mL/Kg/min/watt) }\end{array}$ & $182 \pm 32$ & $163 \pm 32$ & $184 \pm 36$ & $156 \pm 32$ & 0.006 & 0.482 & 0.149 \\
\hline
\end{tabular}

$\mathrm{PL}=$ placebo; T/N-GITS=telmisartan/nifedipine-GITS; VO2=oxygen consumption. 
Figure S1. CONSORT flow diagram.

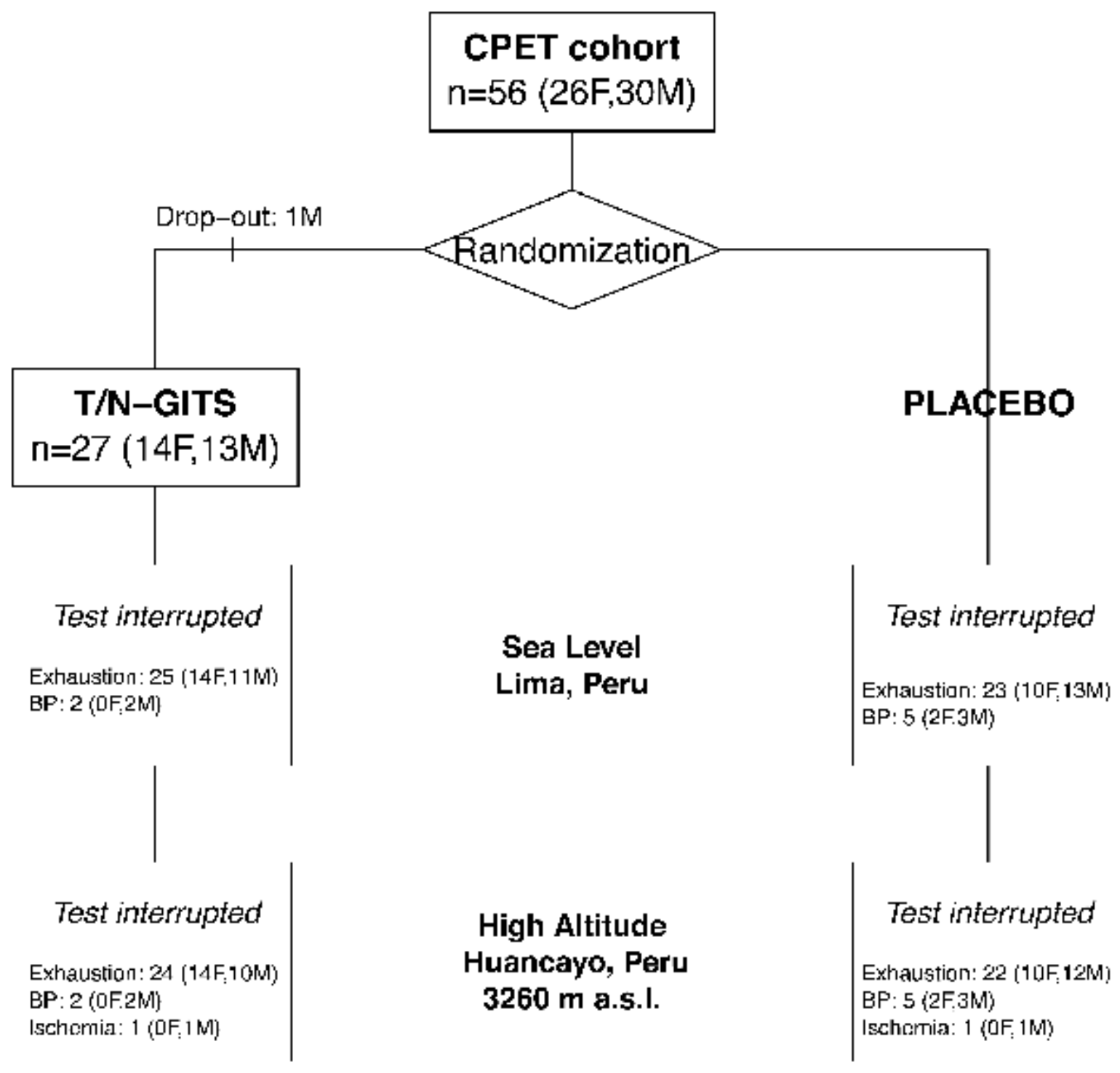

Reasons for cardiopulmonary exercise test interruption (exhaustion, blood pressure or signs/symptoms of myocardial ischemia) are shown for the different study conditions and according to the treatment groups. CPET=cardiopulmonary exercise test; $\mathrm{M}=$ males; $\mathrm{F}=$ females; $\mathrm{T} / \mathrm{N}-\mathrm{GITS}=$ telmisartan $80 \mathrm{mg}+$ nifedipine Gastro-Intestinal Therapeutic System 30 mg; SL=sea level; HA=high altitude; BP=blood pressure. 
Figure S2. Relationship between oxygen consumption and workload in the two treatment groups in the different study conditions.

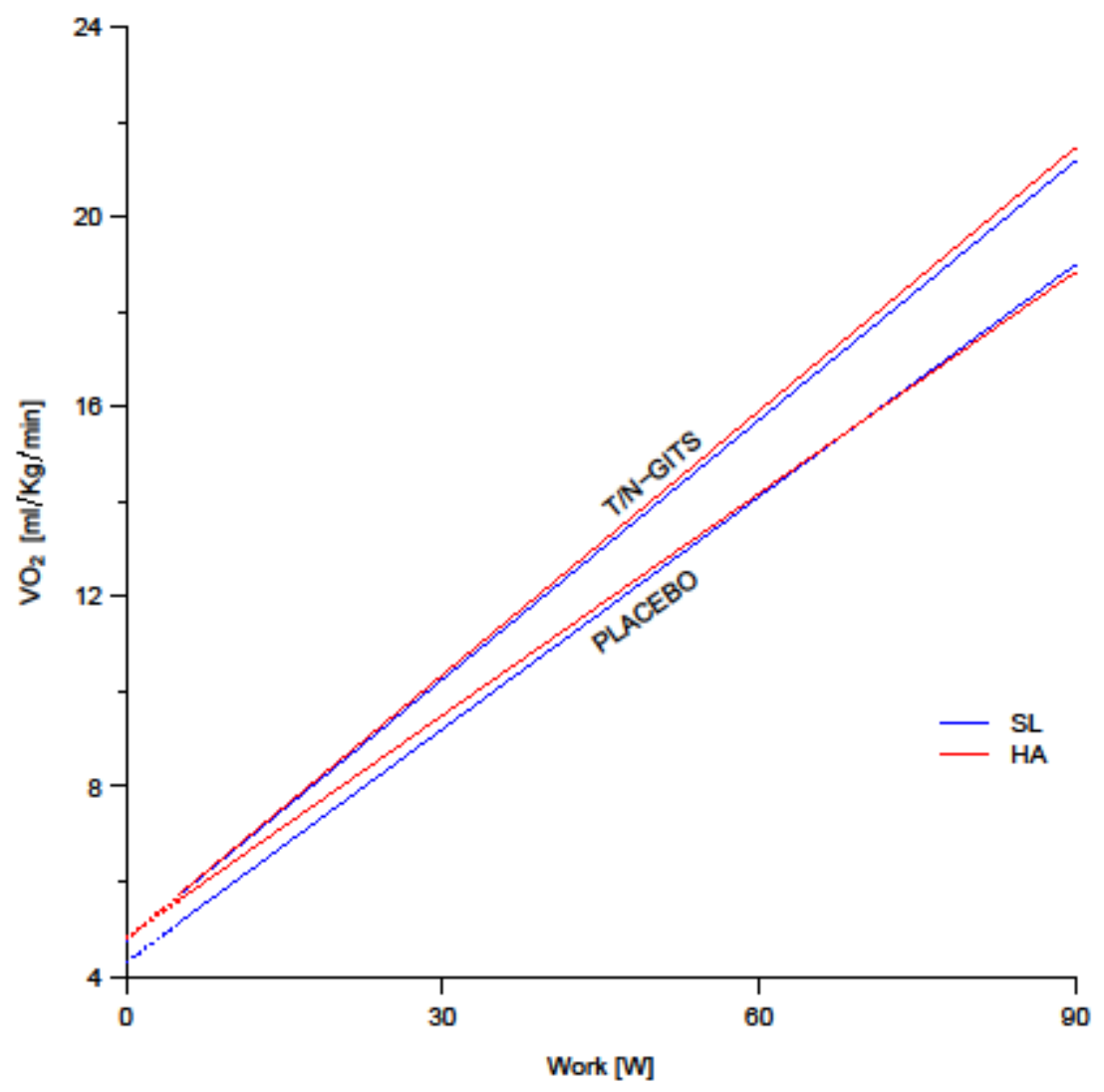

Continuous lines represent the mean slope value for each treatment group both at sea level (in blue) and at altitude (in red) in a physiological range of workload. Dashed lines represent extrapolation until the oxygen consumption intercept on the $y$-axis. HA=high altitude; $\mathrm{SL}=$ sea level; $\mathrm{T} / \mathrm{N}$-GITS=telmisartan 80 $\mathrm{mg} /$ nifedipine-GITS $30 \mathrm{mg}$; VO2=oxygen consumption 


\section{Supplemental References:}

1. Bilo G, Villafuerte FC, Faini A, Anza-Ramírez C, Revera M, Giuliano A, Caravita S, Gregorini F, Lombardi C, Salvioni E, Macarlupu JL, Ossoli D, Landaveri L, Lang M, Agostoni P, Sosa JM, Mancia G, Parati G. Ambulatory Blood Pressure in Untreated and Treated Hypertensive Patients at High Altitude: The High Altitude Cardiovascular Research-Andes Study. Hypertension. 2015;65:1266-72.

2. American Thoracic Society / American College of Chest Physician. ATS/ACCP statement on cardiopulmonary exercise testing. Am J Respir Crit Care Med. 2003;167:211-277.

3. Wasserman K, Hansen JE, Sue DY, Stringer WW, Whipp BJ. Principles of Exercise Testing and Interpretation. 4th ed. Philadelphia, Pa: Lippincott Williams \& Wilkins; 2005. 